\title{
Cystic Dystrophy in Heterotopic Pancreas Mimicking a Gastrointestinal Stromal Tumor
}

\author{
Cheng-Ju Yu', Wen-Hsin Huang1*, Mei-Due Yang ${ }^{2}$, I-Ping Chiang ${ }^{3}$ and Cheng-Yuan Peng1 \\ ${ }^{1}$ Department of Internal Medicine, Taiwan \\ ${ }^{2}$ Department of Surgery, Taiwan
}

${ }^{3}$ Department of Pathology, Taiwan

*Corresponding author: Wen-Hsin Huang, Division of Hepatogastroenterology, Department of Internal Medicine, No 2, Yuh-Der

Road, Taichung 40447, Taiwan

\begin{tabular}{|c|c|}
\hline ARTICLE INFO & ABSTRACT \\
\hline $\begin{array}{l}\text { Received: March 26, } 2019 \\
\text { Published: } \text { 慧 April 08, } 2019\end{array}$ & $\begin{array}{l}\text { Cystic dystrophy in heterotopic pancreas (CDHP), an uncommon complication of } \\
\text { dilated ectopic pancreatic ducts in the heterotopic pancreas, is difficult to diagnose and }\end{array}$ \\
\hline $\begin{array}{l}\text { itation: Cheng-Ju Yu, Wen-Hsin } \\
\text { uang, Mei-Due Yang, I-Ping Chiang, } \\
\text { heng-Yuan Peng. Cystic Dystrophy in }\end{array}$ & $\begin{array}{l}\text { was misdiagnosed as gastric gastrointestinal stromal tumor with endoscopic ultrasound } \\
\text { to highlight the possibility of such diagnosis in all patients with gastric subepithelial } \\
\text { tumors. }\end{array}$ \\
\hline
\end{tabular}
Pancreas Mimicking a Gastrointestinal Stromal Tumor. Biomed J Sci \& Tech Res 16(5)-2019. BJSTR.

Keywords: Heterotopic pancreas; Cystic dystrophy; Stomach; Endoscopic ultrasonography; Gastrointestinal stromal tumor; Gastric subepithelial tumor MS.ID.002914.

\section{Introduction}

Cystic dystrophyin heterotopicpancreas(CDHP)is characterized by the presence of cystic dilatation of the ectopic pancreatic ducts in heterotopic pancreas, which mostly occurs in the second portion of the duodenum [1,2]. Clinical manifestations of CDHP vary greatly and the diagnosis is difficult. Endoscopic ultrasonography (EUS) is regarded as the most useful investigation for the diagnosis of CDHP. We present a patient with symptomatic CDHP in the stomach that was misdiagnosed as gastric gastrointestinal stromal tumor (GIST) with EUS and CT scan.

\section{Case Report}

A 23-year-old non-alcoholic man was referred to the hospital because of a history of 3-week postprandial epigastric fullness and a gastric submucosal tumor. There was no abdominal pain, vomiting, acid regurgitation, constipation, anorexia or weight loss. Physical examination and laboratory studies were unremarkable. An upper gastrointestinal endoscopy showed a polypoid tumor, measuring approximately $2.5-3.0 \mathrm{~cm}$, with a smooth surface in the prepyloric antrum (Figure 1). The gastric submucosal tumor partially obstructed the pylorus. An EUS revealed a homogeneously hypoechoic to anechoic lesion in the fourth sonographic layer of the gastric wall (Figure 2). CT scan of the abdomen also depicted a submucosal tumor in the gastric antrum. The image studies were suggestive of a diagnosis of GIST in the stomach. Therefore, the patient underwent surgical laparotomy with local resection of the tumor. Operative findings demonstrated a submucosal tumor, 26x20x16 mm in size, with an intact capsule, mucus-like content and ductal structures in the posterior wall of prepyloric antrum. Histopathologic examination of the excised specimen showed a heterotopic pancreas composed of acini, large ducts and smooth muscle bundles located in the muscular layer ((Figure 3A \& 3B, 3H $\& 3 E$ ), orig. mag., $\times 20$ and $\times 200$ ), which was compatible with the diagnosis of cystic dystrophy in heterotopic pancreas. The symptom of postprandial abdominal fullness of the patient improved after operation. No recurrence was detected after 18 months follow-up. 


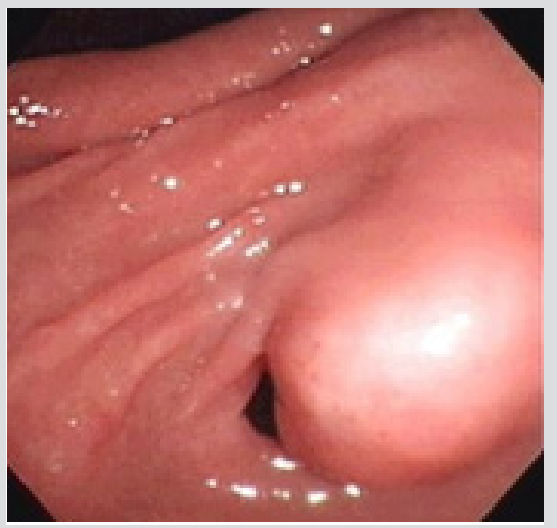

Figure 1: Endoscopic image shows a polypoid tumor with a smooth surface in the prepyloric antrum. The submucosal tumor nearly obstructed the pylorus.

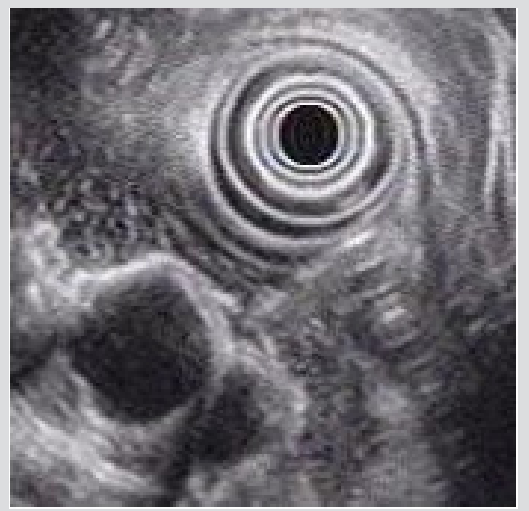

Figure 2: Endosonographic view of a homogeneously hypoechoic to anechoic lesion in the fourth sonographic layer of the gastric wall.

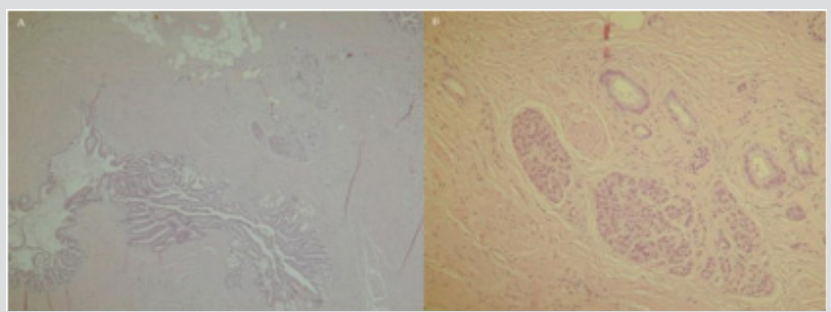

Figure 3: Histopathology reveal a heterotopic pancreas composed of acini, dilated ducts and smooth muscle bundles located in the muscular layer (A and B, H\&E, orig. mag., $\times 20$ and $\times 200$ ).

\section{Discussion}

Heterotopic pancreas, a rare but benign developmental anomaly, is defined as pancreatic tissue that has neither vascular nor anatomic continuity with the normally located pancreas proper [3]. The lesion is usually found incidentally during routine endoscopic examination with an incidence of about one percent and can be readily diagnosed with EUS [4]. Cystic dystrophy developing in heterotopic pancreas is a pathological entity first reported by Potet et al. [5] but was seldom discussed in English literature. It is defined by the presence of cystic formations in the duodenal or gastric wall, intermingled with pancreatic ducts, lobules, and inflammatory lesions $[1,2]$. The mechanism by which the cystic dystrophy occurs in heterotopic pancreas is still not elucidated. Repeated attacks of pancreatitis resulting from obstruction of minor excretory ducts of ectopic pancreatic acini was hypothesized $[2,6]$. CDHP is often associated with chronic pancreatitis and alcoholism [1,7]. Clinical presentation of CDHP varies greatly and the diagnosis remains difficult despite recent advances in imaging techniques. The diagnosis is generally made based on sonographic findings of EUS [1,2].

EUS can identify the structure of intestinal wall, visualize sonographic characteristics of lesion and its layer of origin, and readily diagnose the submucosal tumor [8-10]. At EUS, most GISTs are well circumscribed, hypoechoic and homogenous lesions that arise from the fourth layer (muscularis propri) of gastrointestinal wall. Moreover, CDHP at EUS usually presents as intramural thickening and cystic formations located in the submucosal or muscular layer. The identification of these two different lesions seems not so difficult. However, CDHP may present as the solid pattern as well as the cystic lesion [11]. As the CDHP in our case, mucus-like content within the cystic formation found during operation may lead to the findings of hypoechoic to anechoic echogenicity at EUS, which mimicked the sonographic features of GIST. In addition, GISTs with cystic change that mimicked duplication cyst and cystic mass at EUS have been reported [12,13]. Therefore, duplication cyst and other cystic mass as well as CDHP should be considered in the differential diagnosis of cystic GIST.

Malignant change originating in the CDHP is extremely rare $[1,13]$. Medical treatment, such as parenteral nutrition and octreotide treatment, is the first-line management when the diagnosis of CDHP has been established. However, symptomatic patient with complicated CDHP such as our case is usually recommended to undergo surgical therapy. Although the condition is not common, it should be considered as one of the differential diagnosis in every patient with GIST and other cystic submucosal tumor. In conclusion, CDHP is an uncommon complication of cystic formations in the heterotopic pancreas. EUS may allow preoperative diagnosis. Although EUS is regarded as the most useful tool in evaluating the gastrointestinal submucosal lesions, CDHP, a rare but essential component, should be kept in mind to the differential diagnosis of GIST.

\section{References}

1. Tison C, Regenet N, Meurette G, Mirallié E, Cassagnau E, et al. (2007) Cystic dystrophy of the duodenal wall developing in heterotopic pancreas: report of 9 cases. Pancreas 34(1): 152-156.

2. Fléjou JF, Potet F, Molas G, Bernades P, Amouyal P, et al. (1993) Cystic dystrophy of the gastric and duodenal wall developing in heterotopic pancreas: an unrecognised entity. Gut 34(3): 343-347.

3. Feldman M, Friedman LS, Sleisenger MH (2006) Anatomy, histology, embryology, and developmental anomalies of the pancreas. Sleisenger \& Fordtran's gastrointestinal and liver disease. Saunders Elsevier, pp. 1183-1184. 
4. Chen SH, Huang WH, Feng CL, Chou JW, Hsu CH, et al. (2008) Clinical analysis of ectopic pancreas with endoscopic ultrasonography: an experience in a medical center. J Gastrointest Surg 12(5): 877-881.

5. Potet F, Duclert N (1970) Cystic dystrophy on aberrant pancreas of the duodenal wall. Arch Fr Mal App Dig 59(4): 223-238.

6. Tison C, Leborgne J (2001) Cystic dystrophy of heterotopic duodenal pancreas. J Chir (Paris) 138: 205-214.

7. Vullierme MP, Vilgrain V, Fléjou JF, Zins M, O’Toole D, et al. (2000) Cystic dystrophy of the duodenal wall in the heterotopic pancreas: radiopathological correlation. J Comput Assit Tomogr 24(4): 634-643.

8. Boyce GA, Sivak MV Jr, Rösch T, Classen M, Fleischer DE, et al. (1991) Evaluation of submucosal upper gastrointestinal tract lesions by endoscopic ultrasound. Gastrointest Endosc 37(4): 449-454.

9. Rosch T, Lorenz R, Dancygier H, von Wickert A, Classen M (1992) Endosonographic diagnosis of submucosal upper gastrointestinal tract tumors. Scand J Gastroenterol 27(1): 1-8.

\section{ISSN: 2574-1241}

DOI: 10.26717/BJSTR.2019.16.002914

Wen-Hsin Huang. Biomed J Sci \& Tech Res

(C) This work is licensed under Creative

Submission Link: https://biomedres.us/submit-manuscript.php
10. Zhou PH, Yao LQ Zhong YS, He GJ, Xu MD, et al. (2004) Role of endoscopic miniprobe ultrasonography in diagnosis of submucosal tumor of large intestine. World J Gastroenterol 10(16): 2444-2446.

11. Procacci C, Graziani R, Zamboni G, Cavallini G, Pederzoli P, et al. (1997) Cystic dystrophy of the duodenal wall: radiologic findings. Radiology 205(3): 741-747.

12. Chang CY, Wang HP, Mao TL, Hu RH, Yang PM, et al. (2004) Unusual sonographic appearance of a gastrointestinal stromal tumor presenting as a large multilocular cystic mass. J Clin Ultrasound 32(4): 200-203.

13. Patriti A, Castellani D, Partenzi A, Carlani M, Casciola L (2012) Pancreatic adenocarcinoma in paraduodenal pancreatitis: a note of caution for conservative treatments. Updates Surg 64(4): 307-309.

\begin{tabular}{ll}
\hline $\begin{array}{l}\text { BIOMEDICAL } \\
\text { RESEARCHES }\end{array}$ & Assets of Publishing with us \\
\hline & - \\
\hline
\end{tabular}

